\title{
Management of hyponatremia associated with acute porphyria- proposal for the use of tolvaptan
}

\author{
Isabel Solares ${ }^{1}$, Marta Tejedor ${ }^{2}$, Daniel Jericó ${ }^{3,4}$, Monserrat Morales-Conejo ${ }^{1,5,6,7}$, \\ Rafael Enríquez de Salamanca ${ }^{5}$, Antonio Fontanellas ${ }^{3,4,8}$, Alberto Tejedor-Jorge ${ }^{9}$ \\ ${ }^{1}$ Servicio de Medicina Interna, Hospital 12 de Octubre, Madrid, Spain; ${ }^{2}$ Sección de Hepatología, Hospital Infanta Elena, Valdemoro, Madrid, Spain; \\ ${ }^{3}$ Hepatology Program, Centre for Applied Medical Research (CIMA), University of Navarra, Pamplona, Spain; ${ }^{4}$ Instituto de Investigación Sanitaria \\ de Navarra (IdiSNA), Pamplona, Spain; ${ }^{5}$ Instituto de Investigación Hospital 12 de Octubre, Universidad Complutense, Madrid, Spain; ${ }^{6}$ CSUR de \\ Errores congénitos del Metabolismo, Madrid, Spain; ${ }^{7}$ Centro de Investigación Biomédica en Red de Enfermedades Raras (CIBERER), ${ }^{8}$ Centro de \\ Investigación Biomédica en Red de Enfermedades Hepáticas y Digestivas (CIBEREhd), Instituto de Salud Carlos III, Madrid, Spain; ${ }^{9}$ Cátedra de \\ Nefrología, Universidad Complutense, Madrid, Spain \\ Contributions: (I) Conception and design: I Solares, M Morales-Conejo, R Enríquez de Salamanca, A Fontanellas, A Tejedor-Jorge; (II) Administrative \\ support: None; (III) Provision of study materials or patients: None; (IV) Collection and assembly of data: All authors; (V) Data analysis and \\ interpretation: All authors; (VI) Manuscript writing: All authors; (VII) Final approval of manuscript: All authors. \\ Correspondence to: Dr. Antonio Fontanellas. HepatologyProgram, CIMA-University of Navarra, Avda. Pio XII, 55; 31008Pamplona, Spain. \\ Email: afontanellas@unav.es.
}

\begin{abstract}
Hyponatremia is a common feature during the neurovisceral acute attacks which characterize hepatic porphyrias, as well as a sign of its severity. Therapeutic options for first-line acute attacks are intravenous administration of glucose and/or exogenous heme. The former treatment can aggravate hyponatremia by dilution and cause seizures; thus, the correction of hyponatremia must be carried out with extreme caution. This review summarizes recommendations for the management of hyponatremia during acute episodes of porphyria. Hyponatremia should be corrected slowly and seizures treated with medications in order to not exacerbate motor and sensory axonal neuropathy. The syndrome of inappropriate antidiuretic hormone secretion (SIADH) is considered a frequent cause of hyponatremia in acute porphyrias and must be identified as a symptom of an acute porphyria attack. Tolvaptan produces aquaresis and is considered a safe drug in porphyria. However, its use has only been reported in isolated cases during a porphyria attack. The convenience and usefulness of this drug in acute porphyria are discussed.
\end{abstract}

Keywords: Acute hepatic porphyrias; syndrome of inappropriate antidiuretic hormone secretion (SIADH); hyponatremia; management; tolvaptan

Submitted Feb 11, 2020. Accepted for publication Jul 09, 2020.

doi: 10.21037/atm-20-1529

View this article at: http://dx.doi.org/10.21037/atm-20-1529

\section{Introduction}

Porphyrias are rare metabolic disorders caused by abnormal activity of one of the eight enzymes in the heme biosynthesis pathway and by the respective loss or gain of function mutations in the corresponding genes (Figure 1). Each porphyria has a specific biochemical profile of metabolite accumulation contributing to its diagnosis and typing (1-3).
Acute hepatic porphyrias (AHPs) are characterized by neurovisceral attacks associated with high accumulation of early porphyrin precursors, $\delta$-aminolaevulinic acid (ALA) and porphobilinogen (PBG), of hepatic origin. This group includes acute intermittent porphyria, hereditary coproporphyria and variegate porphyria and result from autosomal dominant loss-of-function mutations in the third,

^ ORCID: Rafael Enríquez de Salamanca, 0000-0003-2556-9546; Antonio Fontanellas, 0000-0001-9279-7990. 


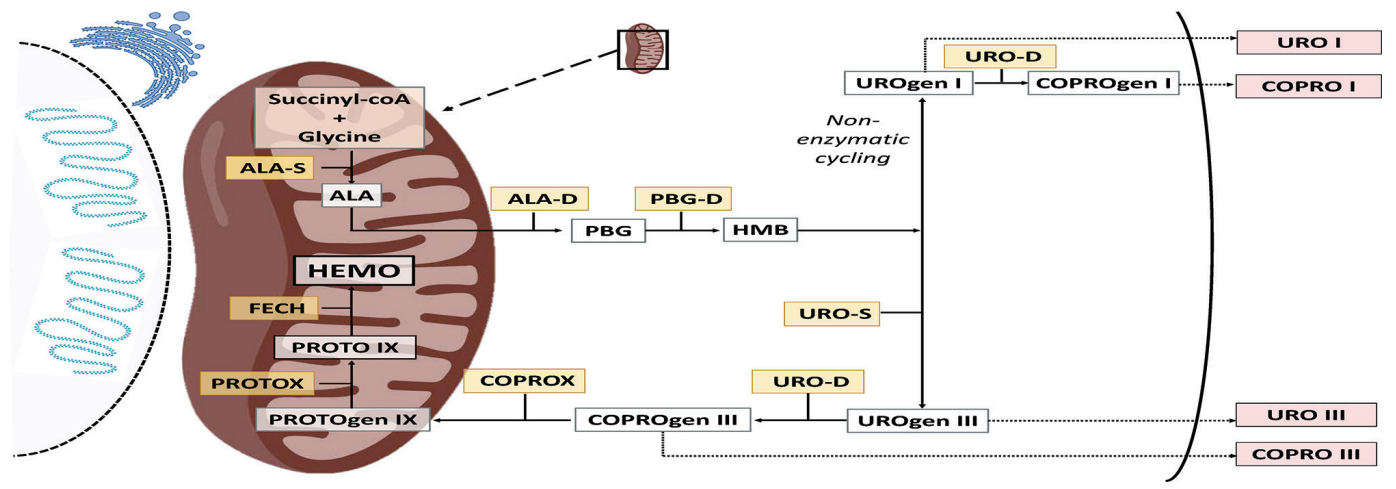

Figure 1 Enzymes and intermediate products of the heme synthesis pathway. Heme synthesis is an important metabolic pathway present in all nucleated cells of the body where its final product is the cofactor of essential hemoproteins involved in biological functions: oxygen binding and transport (myoglobin and hemoglobin), electron transport (cytochromes of the mitochondrial respiratory chain), catalytic decomposition of hydrogen peroxide (peroxidases and catalases), synthesis of steroid hormones and oxidative metabolism of exogenous and endogenous compounds (mitochondrial and microsomal cytochromes of the P450 complex), tryptophan degradation (tryptophan pyrrolase) and nitric oxide synthesis (nitric oxide synthetase). Heme is also essential as substrate for heme oxygenase (HO) to yield carbon monoxide (CO) and biliverdin, which is subsequently reduced to bilirubin by cytosolic biliverdin reductase. CO is a strong vasodilatory, anti-inflammatory and immunomodulatory agent and both biliverdin and bilirubin are efficient scavengers of reactive oxygen species thus reducing the formation of peroxidation products. About $80 \%$ of daily heme synthesis occurs in the erythropoietic lineage and hepatocytes synthesize about $15 \%$ of total daily body heme. A delicate regulation of the route is essential because both heme and its intermediate metabolites are toxic at high concentrations. The ALA-synthetase (ALAS) is the first enzyme and rate-limiting reaction in heme synthesis. It has two isoenzymes, one ubiquitous (ALAS1) and the other erythroid (ALAS2). Heme regulates ALAS1 by a negative feedback mechanism, its translocation to the mitochondria and degradation. ALAS2 is characterized by high steady state level and is tied to availability of iron. In addition, the first four enzymes have specific erythroid and housekeeping promoters. Finally, the pathway is highly compartmentalized, the first and the final three steps are catalyzed by proteins that reside in the mitochondria while the remaining four steps are catalyzed in the cytosol. Each porphyria is caused by a loss or gain function of one of the enzymes involved in the pathway leading to overproduction and accumulation of porphyrins and/or their precursors. Accumulation of early pathway intermediates (ALA and PBG) leads to neurologic symptoms. These simple molecules are exclusively eliminated by urine. Four monopyrrol PBG are cyclized to form a porphyrinogen molecule. Oxidation of these tetrapyrrole rings lacking metal, leads to the fluorescence responsible for the phototoxic effects primarily affecting the skin. Porphyrinogen excretion (and its corresponding oxidized molecule, the porphyrin) is conditioned by their water solubility. While octacarbonyl URO is water-soluble, dicarboxylic PROTO is hydrophobic and is removed by biliary excretion and through the feces. The tetracarboxylic COPRO is preferably eliminated by bile but also by urine. White boxes represent the intermediate products: ALA, $\delta$-aminolaevulinic acid; PBG, porphobilinogen (also known as Hydroxymethylbilane, HMB); UROgen, uroporphyrinogen; COPROgen, coproporphyrinogen; PROTOgen, protoporphyrinogen. Red boxes are porphyrins, resulting from the oxidation of the corresponding porphyrinogens: URO, uroporphyrin; COPRO, coproporphyrin; PROTO, protoporphyrin. Yellow boxes are enzymes: ALA-S, Amino-aminolaevulinic synthase; ALA-D, Aminolaevulinic acid dehydratase; PBGD, Porphobilinogen deaminase (also known as Hydroxymethylbilane Synthase, HMBS); UROS, Uroporphyrinogen III synthase; UROD, Uroporphyrinogen Decarboxylase; COPROX, Coproporphyrinogen Oxidase, PROTOX, Protoporphyrinogen Oxidase; FECH, ferrochelatase.

sixth and seventh enzymes of the heme pathway, respectively (Figure 1). An extremely rare autosomal recessive disorder of the second enzyme, ALA dehydratase porphyria (ADP), characterized by a marked increase in plasma and urine ALA is also included in AHPs.

A marked enzymatic deficiency in ADP is related to its high penetrance and severe symptomatology with onset in childhood (4). In contrast, most gene carriers of the dominant form of AHPs are asymptomatic and precipitating factors are required to trigger acute attacks (5). These precipitating factors, both endogenous and exogenous (6), have in common the induction of the first and rate-limiting step in hepatic heme biosynthesis pathway, the ALA Synthetase (ALAS1), either directly after starvation (via 
peroxisome-proliferator-activated receptor $\gamma$ coactivator $1 \alpha$, PGC- $1 \alpha)$ or through the suppression of the negative feedback mechanism caused by excessive heme consumption to form hemoproteins (mostly inducible cytochrome P450) or by increasing end-product degradation through heme oxygenase-1 (HO-1) induction.

\section{Pathophysiology and management of the porphyric attack}

Acute porphyria attacks are characterized by intense abdominal pain often accompanied by nausea, vomiting, hyponatremia, constipation, hypertension, tachycardia, insomnia and anxiety. Severe attacks can lead to neuropsychiatric disorders, seizures, sensory loss or motor neuropathy (including tetraparesis and life-threatening respiratory muscle failure) (2). Most acute neurovisceral attacks require hospital admission. The presence of seizures, motor neuropathy, and hyponatremia suggest severe disease that ideally should be managed in an intensive care unit.

The current goal of treatment for acute attacks is to reduce the activity of hepatic ALAS1, thus resulting in decreased production of early porphyrin precursors. The administration of intravenous human hemin, (heme arginate, Normosang ${ }^{\circledR}$ in Europe and crystallized hemin, Panhematin ${ }^{\circledR}$ in the US, both from Recordati) downregulates hepatic ALAS1 transcription, inhibits ALAS1 mRNA translation and the translocation of the ALAS1 protein precursor into the mitochondria $(1-3,7,8)$.

Mild attacks (without seizures, weakness, or hyponatremia and not requiring opioids) can sometimes be treated with a glucose overload $(8,9)$ although this is less effective than hemin. Dose-dependent administration of glucose has also been shown to downregulate ALAS1 mRNA transcription in experimental conditions via PGC-1 $\alpha$ (10). Subsequently, glucose infusions have been used to prevent mild attacks. However, this therapy has the disadvantage of aggravating hyponatremia owing to dilution, so this hydroelectrolytic abnormality must be corrected with extreme caution.

\section{Hyponatremia and ADH during the porphyric attack}

Mild to severe hyponatremia is a rather common phenomenon (occurring in $25-60 \%$ of cases) during an acute attack, as well as a marker of the severity of the crisis (11). Major motor seizure occurs in up to $20 \%$ of acute attacks and is often associated with severe hyponatremia. Although undoubtedly the etiology of the acute attack in hepatic porphyrias is the rise in plasma ALA and PBG levels, hyponatremia, as well as the development of a syndrome of inappropriate antidiuretic hormone secretion (SIADH), play a central role in the prognosis of the patient.

Although intestinal losses of $\mathrm{Na}^{+}$during the crisis, or renal losses secondary to a salt-wasting ALA-dependent syndrome may play a role, hyponatremia in AHPs (12) is more likely to be caused by SIADH (13). In fact, elevated plasma levels of $\mathrm{ADH}$ in euvolemic conditions have been observed during acute attacks (14).

The etiology of SIADH in porphyric attacks is probably multifactorial. First, abdominal pain attributed to vascular spasms caused by ALA and PBG is a direct stimulus for the synthesis of $\mathrm{ADH}$ by the parvocellular portion of the paraventricular nucleus (Figure 2) (15). The excess of ADH also acts on the V1a receptors of the vasculature, increasing peripheral resistance and raising central blood pressure, and on the renal V2 receptors, preventing the kidney from adequately eliminating any water overload (16). Second, in the paralytic ileus that frequently accompanies acute attacks; intestinal sequestration of water and electrolytes stimulates the secretion of angiotensin II. The floor of the third ventricle is equipped with receptors for angiotensin II, which are capable of directly stimulating $\mathrm{ADH}$ secretion into the third ventricle through a mechanism known as $\mathrm{ADH}$ secretion by baroreception (Figure 2) (17).

When the attack begins to subside, there is rapid a reabsorption of a significant volume of water and electrolytes from the interstitial space or a third-space to the blood vessels. Sodium is rapidly excreted by the kidney when all natriuretic systems are activated. However, if there is an excess of $\mathrm{ADH}$, water can cause a usually unexpected late hyponatremia. The iatrogenic component should not be forgotten if the intense pain is interpreted as an acute abdomen and an exploratory laparotomy is performed. Simple surgical manipulation is a direct stimulus for hypothalamic secretion of ADH. In addition, abdominal surgery produces a mean decrease in natremia of between 5 and $6 \mathrm{mmol} / \mathrm{L}$, or greater when there is underlying SIADH (18).

Finally, the majority of deaths recorded during acute attacks of porphyria have been reported in relation to hypoxemia due to respiratory paralysis. The cerebral defense against the hypotonic edema, which follows the development of acute hyponatremia, is based on the activity of an astrocyte sodium pump. Hypoxia inhibits this pump; thus the prognosis of hyponatremia worsens when there are 


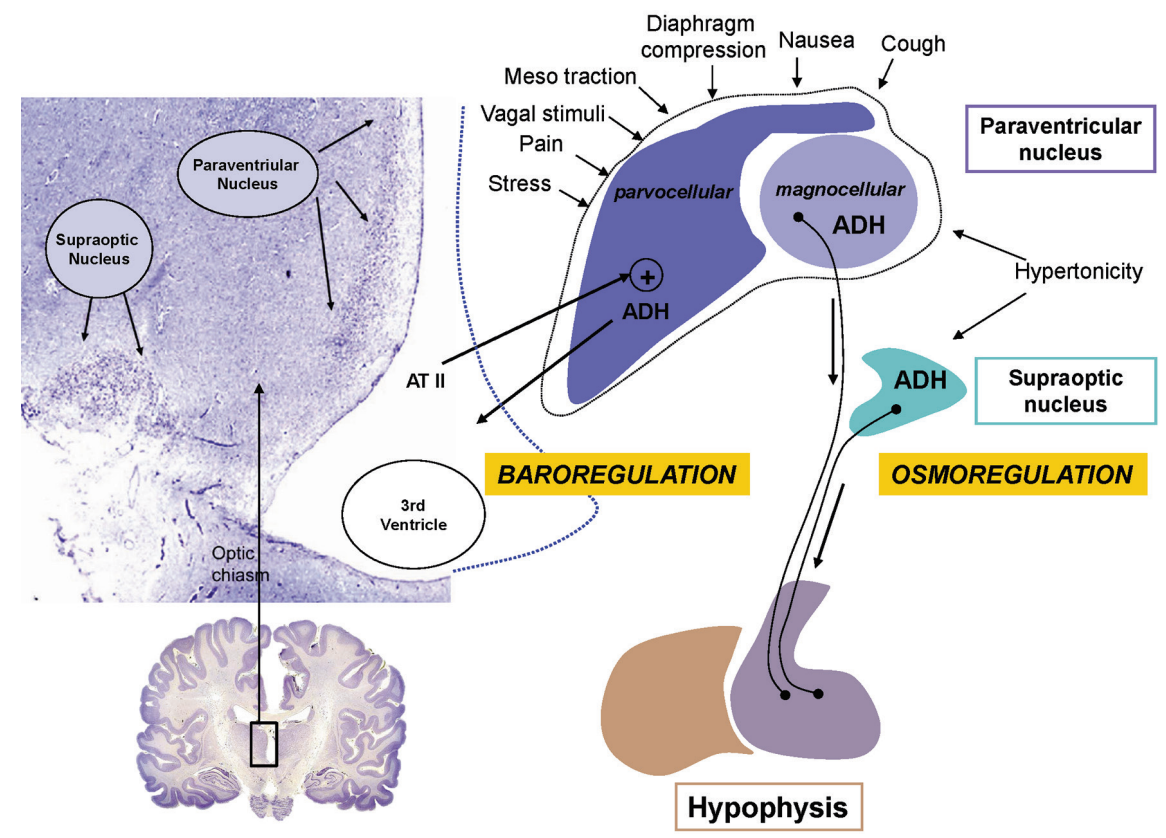

Figure 2 Schematic representation of the secretion of ADH by the supraoptic and paraventricular nucleus. The supraoptic nucleus and the magnocellular portion of the paraventricular nucleus, whose axons constitutes the stem of the pituitary gland, discharge ADH into the neurohypophysis in response to elevations in the plasma osmolarity (Osmoregulation). Paraventricular nucleus responds with simultaneous secretion of $\mathrm{ADH}$ to the third ventricle in response to pain, stress, cough, nausea and in response to mechanical stimuli in the diaphragm. The floor of the third ventricle has angiotensin II receptors that justify the secretion of ADH in situations of hypovolemia greater than $10 \%$ ("Baroregulation"). ADH, antidiuretic hormone; AT II, angiotensin II.

respiratory difficulties.

\section{The "glucose effect" and the complications derived from its application in the treatment of acute attacks}

High doses of glucose ( $>500 \mathrm{~g} /$ day) effectively suppress the hepatic ALAS1 promoter (19). The "glucose effect" in acute hepatic porphyrias was first described by Kaufman (20). To be useful, the minimum glucose infusion should reach 300 $500 \mathrm{~g} /$ day. However, a rise in glycemia tends to produce a pseudo-hyponatremia that makes it difficult to adequately interpret what fraction of the reduction in natremia is due to SIADH or is secondary to the rise in glucose. Therefore, when hyponatremia is detected during a hepatic porphyria attack, it is necessary to correct the apparent hyponatremia by adjusting the glucose concentration (21) to reveal the real value of the natremia.

Corrected Nap $=$ Nap measured $+(($ blood glucose $(\mathrm{mg} / \mathrm{dL})-100) / 63)$

The volume of dextrose solution administered can be very high when $5 \%$ glucose is used to administer $300-500 \mathrm{~g} /$ day $(6-10 \mathrm{~L} / \mathrm{day})$. Although the use of $10 \%$ glucose allows the dose to be reduced to $3-5 \mathrm{~L} /$ day, it remains a very high volume when the patient has SIADH because renal excretion of electrolyte-free water is impaired.

\section{Proposal for the treatment of hyponatremia during an acute attack of porphyria}

(I) Check for hypoxemia and proceed to its immediate correction.

(II) Exclude adrenal insufficiency as a contributing factor in the etiology of the hyponatremia. During the attack of acute porphyria, other abnormalities in the hypothalamic-pituitary axis have been reported, other than SIADH, such as growth hormone alteration, hyperprolactinemia and Adrenocorticotropic hormone (ACTH) deficit (22).

(III) If the patient tolerates oral treatment, $5-8 \mathrm{~g}$ of oral $\mathrm{NaCl}$ administered in two doses can be an option.

(IV) When intravenous therapy is necessary, it is 
preferable to administer $\mathrm{NaCl}$ to a concentration higher than $0.9 \%$, to avoid volume overload. The current recommendation is to use $3 \% \mathrm{NaCl}$, which is obtained by adding $30 \mathrm{~mL}$ of $20 \% \mathrm{NaCl}$ to $250 \mathrm{~mL}$ of $0.9 \% \mathrm{NaCl}$ solution. It is not advisable to use higher concentrations as they increase the risk of excessive hypercorrection and osmotic demyelination. The $3 \% \mathrm{NaCl}$ infusion is started at $10 \mathrm{~mL} / \mathrm{h}$, and can be increased to up to $50 \mathrm{~mL} / \mathrm{h}$ depending on the symptoms. This medication should be used with caution and close monitoring to prevent hypercorrection. The objective is not the complete correction of hyponatremia, but to avoid the risk of intracerebral compression due to hypotonic edema. In the case of a rapid progression of the neurological symptomatology, a bolus of $50 \mathrm{~mL}$ of saline $3 \%$ can be administered, which can be repeated after 10 minutes when no clinical improvement is observed.

Natremia should be monitored every $2-4 \mathrm{~h}$ and the infusion should be suspended when:

* $126 \mathrm{mmol} / \mathrm{L}$ are reached in patients starting with natremias $\leq 125 \mathrm{mmol} / \mathrm{L}$.

* Natremia has risen $>5 \mathrm{mmol} / \mathrm{L}$ in one day.

The therapeutic goal in the first $24 \mathrm{~h}$ is to raise the natremia between 5 and $6 \mathrm{mmol} / \mathrm{L}$, reaching $125 \mathrm{mmol} / \mathrm{L}$ when the baseline hyponatremia was lower or achieve $132 \mathrm{mmol} / \mathrm{L}$ when the natremia was between 130 and $125 \mathrm{mmol} / \mathrm{L}$. However, these criteria in the treatment algorithms of acute hyponatremia exhibit two clinical peculiarities in the case of hyponatremia associated with an acute hepatic porphyria attack:

(i) Usually the patient has high blood pressure $(1,2)$, so salt overload can cause pulmonary congestion and hypoxemia. Therefore, a volume of $250 \mathrm{~mL}$ of $3 \% \mathrm{NaCl}$ is recommended, in order to avoid the harmful effects caused by large quantities of $\mathrm{NaCl}$.

(ii)In patients treated with a glucose infusion and who are receiving between 3-10 L/day of water and glucose (depending on the concentration used), the kidney is capable of removing up to $20 \mathrm{~L}$ of water per day $(1.5 \mathrm{~L} / \mathrm{h})$. However, it is required a minimum amount of $50 \mathrm{mOsm}$ for the disposal of each liter of water. The induced glycosuria can reduce the excretion of free water, and there is also a minimum loss of $\mathrm{Na}^{+}$of $25 \mathrm{mmol} / \mathrm{L}$. Depending on the dextrose solution administered, the dilutive capacity of the kidney can be easily exceeded, even with a $3 \% \mathrm{NaCl}$ infusion. Thus, the result is the development of hyponatremia.

(V) Water restriction in a patient who requires high volumes of infusion of dextrose solution is not an option.

(VI) The last treatment option is the increase in free water clearance using tolvaptan (ATC code: C03XA01).

\section{Use of tolvaptan in SIADH}

Treatment with anticonvulsants can be challenging in AHPs, because many of the commonly used anticonvulsants (carbamazepines, hydantoins, valproate, etc.) cause up-regulation of hepatic ALAS1 and can precipitate and/or worsen acute porphyric attacks (23).

Tolvaptan is a selective ADH antagonist, which acts by binding to renal vasopressin V2 receptor (24). It is administered orally and produces specific aquaresis without changes in the $\mathrm{Na}^{+}$balance. It is the only $\mathrm{ADH}$ inhibitor available in Europe. It has been shown to be useful in hyponatremia associated with SIADH of any etiology, and in hyponatremia associated with heart failure, liver disease (24) and post-operative situations resulting from different surgeries (25).

The use of tolvaptan in SIADH is recommended when the following criteria are met: (I) existence of true hyponatremia after correcting plasma natremia by glucose, protein or lipid levels (corrected Natremia $<130 \mathrm{mmol} / \mathrm{L}$ ); (II) urinary osmolarity $>100 \mathrm{mOsm} / \mathrm{kg}$. Hyponatremia with lower urinary osmolarities are considered secondary to excessive water intake; (III) a urinary $\mathrm{Na}^{+}$concentration of $>40 \mathrm{mmol} / \mathrm{L}$. Lower concentrations of urinary $\mathrm{Na}^{+}$are considered secondary to hypovolemia; and (IV) in those cases when thyroid and adrenal insufficiency has been adequately ruled out.

Tolvaptan is formulated in tablets of 15 and $30 \mathrm{mg}$, with daily doses ranging between 7.5 and $60 \mathrm{mg}$, always administered in a single dose (26). The duration of its effect is $8-12 \mathrm{~h}$ during which aquaresis increases significantly, thus it is usually administered in the morning. It is recommended to start treatment with $7.5 \mathrm{mg}$ and then titrate the dose according to response. In most cases, the dose of $7.5 \mathrm{mg}$ is adequate $(26,27)$. Hypercorrection is exceptional and natremia is usually normalized in a period of 3 to 10 days. Given the irregularity of the response to the first dose, its use is not recommended in the first $24 \mathrm{~h}$ 
following the development of hyponatremia. Oral salt or the administration of $3 \% \mathrm{NaCl}$ is the preferred option for that period of time.

Tolvaptan is metabolized by the cytochrome CYP3A4 in the liver. It is considered as a "Probably Not Porphyrinogenic" drug for porphyria (6), and was well tolerated during a porphyric attack, as reported in isolated cases. One of these cases has been reported recently (28). A 13-year-old Indian boy developed an acute porphyric attack after starting treatment with tuberculostatic. At first, laboratory studies showed hyponatremia at $114 \mathrm{mmol} / \mathrm{L}$ and urinary sodium and osmolality confirmed the diagnosis of SIADH. The patient received tolvaptan, antihypertensives, levetiracetam and opioids. His mental state and hyponatremia progressed favorably, but he developed an ascending areflexic paralysis of all four limbs with respiratory involvement. Then, high urinary excretion of PBG established the diagnosis of acute porphyria. As hemin was not available, treatment was based on IV glucose $10-20 \mathrm{mg} / \mathrm{h}$ in combination with tolvaptan that led to a progressive improvement in motor symptoms, with no further deterioration of natremia.

Natremia monitoring during the acute attack should be performed every 2-4 h, to detect rapid hypercorrections, especially when $3 \%$ hypertonic saline is being used. In case of hypercorrection, these instructions should be followed: (I) supply water; (II) suspend the $3 \%$ saline infusion; (III) omit the next dose of tolvaptan; (IV) infuse $5 \%$ glucose therapy at a rate of $6 \mathrm{~mL} / \mathrm{kg} / \mathrm{h}$ for $2 \mathrm{~h}$; and then, measure the natremia; and (V) if no improvement occurs, administer desmopressin 1-2 mg subcutaneously or intravenously every 6 hours.

The duration of tolvaptan treatment depends on the nature of the SIADH and the underlying disease, and it is recommended to be used for no longer than 30 days (U.S. Food and Drug Administration). Tolvaptan can be suspended when plasma $\mathrm{Na}^{+}$rises to a level between 132 and $140 \mathrm{mmol} / \mathrm{L}$, without progressive dose reduction. In the case of acute hepatic porphyria, its indication will only be maintained for the duration of the acute condition. Usually the acute porphyria attacks last 5 to 7 days (29), and the persistence of symptomatic hyponatremia beyond the crisis is unusual. In other situations with chronic SIADH (senile hyponatremia, tumors...) maintenance treatment is frequently achieved with a dose of $7.5 \mathrm{mg}$ every/48 or 72 h chronically (26).

It is likely that tolvaptan may be part of the treatment of acute porphyria attack, especially if there is hyponatremia and it is necessary to increase the clearance of free water to safely handle high volumes of dextrose solution.
However, its effectiveness may be reduced in the presence of large glucose infusions with glucosuria that reduce the concentration gradient between the tubular lumen and the interstitium of the renal papilla. For this reason, urea does not work in porphyria hyponatremia when glucosated sera are used.

In conclusion, electrolyte imbalances, and especially hyponatremia, should be corrected and monitored during acute episodes of porphyria. Precautions against convulsions and seizures are recommended, especially in patients who develop hyponatremia. This often results from hypothalamic involvement and SIADH or excess gastrointestinal or renal sodium loss. Although patients who experience seizures during an acute attack seldom require anticonvulsant therapy; treatment is difficult since common anticonvulsants could be harmful in AHPs and, most importantly, they do not resolve the underlying hyponatremia. Thus, we propose the use of tolvaptan for the treatment of hyponatremia in acute porphyria under the strict conditions specified in this review.

\section{Acknowledgments}

In memoriam of Dr. Alberto Tejedor, sadly deceased during the COVID19 pandemic. May his memory guide our path in the management of hyponatremia and acid-base disorders.

Funding: This work was supported in part by grants from Spanish Institute of Health Carlos III (FIS) cofunded by European FEDER funds (grant numbers PI18/00860), the Spanish Fundación Eugenio Rodríguez Pascual, the Spanish Fundación Mutua Madrileña and the Spanish Fundación FEDER para la investigación de enfermedades raras. The founders had no role in the analysis or the development of conclusions. The investigators are solely responsible for the content and the decision to submit the manuscript for publication.

\section{Footnote}

Conflicts of Interest: All authors have completed the ICMJE uniform disclosure form (available at http://dx.doi. org/10.21037/atm-20-1529). The authors have no conflicts of interest to declare.

Etbical Statement: The authors are accountable for all aspect of the work in ensuring that questions related to the accuracy or integrity of any part of the work are 
appropriately investigated and resolved.

Open Access Statement: This is an Open Access article distributed in accordance with the Creative Commons Attribution-NonCommercial-NoDerivs 4.0 International License (CC BY-NC-ND 4.0), which permits the noncommercial replication and distribution of the article with the strict proviso that no changes or edits are made and the original work is properly cited (including links to both the formal publication through the relevant DOI and the license). See: https://creativecommons.org/licenses/by-nc-nd/4.0/.

\section{References}

1. Puy H, Gouya L, Deybach JC. Porphyrias. Lancet 2010;375:924-37.

2. Bissell DM, Anderson KE, Bonkovsky HL. Porphyria. N Engl J Med 2017;377:862-72.

3. Pischik E, Kauppinen R. An update of clinical management of acute intermittent porphyria. Appl Clin Genet 2015;8:201-14.

4. Neeleman RA, van Beers EJ, Friesema EC, et al.Clinical Remission of Delta-Aminolevulinic Acid Dehydratase Deficiency Through Suppression of Erythroid Heme Synthesis. Hepatology 2019;70:434-6.

5. Chen B, Whatley S, Badminton M, et al. International Porphyria Molecular Diagnostic Collaborative: an evidence-based database of verified pathogenic and benign variants for the porphyrias. Genet Med 2019;21:2605-13.

6. Database. Drugs database and acute porphyrias. Available online: http://www.drugs-porphyria.org/monograph2 . php?id=5458; last entry: April 9th, 2020.

7. Schmitt C, Lenglet H, Yu A, et al. Recurrent attacks of acute hepatic porphyria: major role of the chronic inflammatory response in the liver. J Intern Med 2018;284:78-91.

8. Balwani M, Wang B, Anderson KE, et al. Acute hepatic porphyrias: Recommendations for evaluation and longterm management. Hepatology 2017;66:1314-22.

9. Castelbón Fernández FJ, Solares Fernandez I, Arranz Canales E, et al. Protocol For Patients With Suspected Acute Porphyria. Rev Clin Esp 2020. [Epub ahead of print].

10. Handschin C, Lin J, Rhee J, et al. Nutritional regulation of hepatic heme biosynthesis and porphyria through PGC1alpha. Cell 2005;122:505-15.

11. Stein PE, Badminton MN, Rees DC. Update review of the acute porphyrias. Br J Haematol 2017;176:527-38.
12. Jaramillo-Calle DA, Solano JM, Rabinstein AA, et al. Porphyria-induced posterior reversible encephalopathy syndrome and central nervous system dysfunction. Mol Genet Metab 2019;128:242-53.

13. Meersseman W, Cassiman D, Goossens W, et al. An unusual cause of syndrome of inappropriate antidiuretic hormone secretion. Acta Clin Belg 2008;63:277-80.

14. Eales L, Dowdle EB, Sweeney GD. The acute porphyric attack. I. The electrolyte disorder of the acute porphyric attack and the possible role of delta-aminolaevulic acid. S Afr Med J 1971;89-97.

15. Buggy J, Fisher AE. Anteroventral third ventricle site of action for angiotensin induced thirst. Pharmacol Biochem Behav 1976;4:651-60.

16. Greenberg A, Verbalis JG. Vasopressin receptor antagonists. Kidney Int 2006;69:2124-30.

17. Kubo T, Numakura H, Endo S, et al. Angiotensin receptor blockade in the anterior hypothalamic area inhibits stress-induced pressor responses in rats. Brain Res Bull 2001;56:569-74.

18. Caramelo C, Tejedor A, Criado C, et al. Fluid therapy in surgical patients: composition and influences on the internal milieu. Nefrologia 2008;28:37-42.

19. Tschudy DP, Welland FH, Collins A, et al. The Effect of Carbohydrate Feeding on the Induction of Delta-Aminolevulinic Acid Synthetase. Metabolism 1964;13:396-406.

20. Kaufman L, Marver HS. Biochemical defects in two types of human hepatic porphyria. N Engl J Med 1970;283:954-8.

21. Katz MA. Hyperglycemia-induced hyponatremia-calculation of expected serum sodium depression. N Engl J Med 1973;289:843-4.

22. Waxman AD, Berk PD, Schalch D, et al. Isolated adrenocorticotrophic hormone deficiency in acute intermittent porphyria. Ann Intern Med 1969;70:317-23.

23. Anderson KE, Bloomer JR, Bonkovsky HL, et al. Recommendations for the diagnosis and treatment of the acute porphyrias. Ann Intern Med 2005;142:439-50.

24. Schrier RW, Gross P, Gheorghiade M, et al. Tolvaptan, a selective oral vasopressin V2-receptor antagonist, for hyponatremia. N Engl J Med 2006;355:2099-112.

25. Nakamura Y, Kishimoto Y, Harada S, et al. Tolvaptan can limit postoperative paroxysmal atrial fibrillation occurrence after open-heart surgery. Surg Today 2020;50:841-8.

26. Castello LM, Baldrighi M, Panizza A, et al. Efficacy and safety of two different tolvaptan doses in the treatment of hyponatremia in the Emergency Department. Intern 
Page 8 of 8

Emerg Med 2017;12:993-1001.

27. Cuesta M, Gomez-Hoyos E, Montañez C, et al. An initial dose of $7.5 \mathrm{mg}$ Tolvaptan is safe and effective in the treatment of hyponatremia caused by SIADH. Endocrine Abstracts 2012;29:P1149.

28. Golla R, Mukherjee A, Gone RK, et al. Acute intermittent

Cite this article as: Solares I, Tejedor M, Jericó D, Morales-Conejo M, Enríquez de Salamanca R, Fontanellas A, Tejedor-Jorge A. Management of hyponatremia associated with acute porphyria - proposal for the use of tolvaptan. Ann Transl Med 2020;8(17):1098. doi: 10.21037/atm-20-1529
Solares et al. Hyponatremia management in acute porphyrias.

porphyria and anti-tuberculosis therapy. QJM 2020;113:207-8.

29. Gouya L, Ventura P, Balwani M, et al. EXPLORE: A Prospective, Multinational, Natural History Study of Patients with Acute Hepatic Porphyria with Recurrent Attacks. Hepatology 2020;71:1546-58. 